\title{
Direitos sociais na constituição cidadã: um balanço de 21 anos $^{*}$
}

\author{
Social rights in the citizen Constitution: a balance \\ of twenty-one years of existence
}

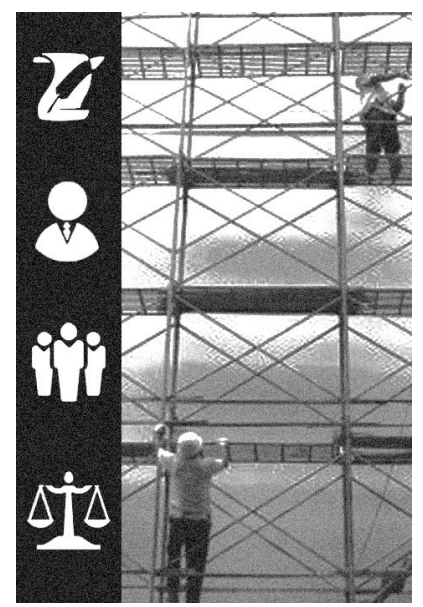

\section{Carlindo Rodrigues de Oliveira** Regina Coeli de Oliveira**}

\begin{abstract}
Resumo: O presente trabalho faz um balanço dos direitos sociais previstos na Constituição de 1988, destacando seus avanços e limitações ao longo destes últimos 21 anos. Começando pelos direitos dos trabalhadores e, em seguida, pelos dispositivos relativos à Seguridade Social, o trabalho busca compreender as motivações do legislador constituinte e o histórico de constantes disputas no interior da sociedade, em torno da regulamentação, manutenção e aprimoramento desses direitos ao longo dos anos.
\end{abstract}

Palavras-chave: Constituição. Direitos sociais. Seguridade social.

\begin{abstract}
This paper is an attempt to make a balance of the social rights forseen in the Brazilian 1988 Constitution, stressing its advances and limitations during the last twenty one years. Beginning with the labour rights and following with the Social Security articles, it is an effort to understand both the motivations of the legislators and the historic of permanent disputes within the Brazilian society around the regulation, maintenance and improvement of these rights along the years.
\end{abstract}

Keywords: Constitution. Social rights. Social security

* Artigo originalmente apresentado no X Encontro Nacional da Associação Brasileira de Estudos do Trabalho (Abet), com o tema "A crise mundial e os dilemas do trabalho", realizado de 28 de setembro a $1^{\circ}$ de outubro de 2009, em Campinas (SP).

** Economista, mestre em Ciência Política pela UFMG - Belo Horizonte/MG, Brasil e técnico do Departamento Intersindical de Estatística e Estudos Socioeconômicos (Dieese).E-mail: carlindo.rodrigues@, yahoo.com.br.

*** Assistente social, mestre em Serviço Social pela Universidad Nacional Autónoma de Honduras e professora da Escola de Serviço Social da Pontifícia Universidade Católica de Minas Gerais - PUC Minas — Belo Horizonte/MG, Brasil.E-mail: reginacoelioliveira@yahoo.com.br. 


\section{Introdução}

$\mathrm{N}$ o dia 5 de outubro de 2009, a Constituição Federal completou 21 anos de vigência, atingindo, portanto, a maioridade. Conhecida como a "Constituição Cidadã", mereceu essa alcunha em virtude da inclusão, como direitos fundamentais, de uma série de direitos sociais que a colocaram em contemporaneidade com os anseios da sociedade brasileira, após 42 anos de vigência da Constituição Federal de setembro de 1946, última promulgada sob regime democrático.

Criticada por uns, pelo detalhismo de suas disposições, justifica-se essa sua característica pela tradição de alto grau de descumprimento da legislação ordinária no país, a exemplo do que ocorre com a legislação trabalhista criada nas décadas de 1930 e 1940 e inscrita na Consolidação das Leis do Trabalho - CLT —, cujo cumprimento ainda é motivo de frequentes demandas judiciais por parte dos trabalhadores.

O presente artigo visa avaliar os avanços introduzidos na Constituição, em seus artigos $1^{\circ}$ e $3^{\circ}$ (Princípios Fundamentais); artigos $7^{\circ}$ a 11 (Dos Direitos e Garantias Fundamentais, Capítulo II, dos Direitos Sociais); artigo 165 (dos Orçamentos, parágrafo $5^{\circ}$ ) e artigos 193 a 204 (Da Ordem Social, Capítulos I e II, da Seguridade Social). Visa, também, analisar os desafios para que essas conquistas da legislação sejam integralmente implementadas.

Esses avanços foram obtidos graças à organização e mobilização de expressivos segmentos da sociedade brasileira, desde meados da década de 1970, sendo que entre as bandeiras democráticas colocadas por esses segmentos estava a de uma Constituinte livre e soberana. Instalou-se, no entanto, um Congresso Nacional Constituinte, eleito em 1986, com uma composição predominantemente conservadora, no contexto do governo Sarney e sob a euforia do Plano Cruzado de estabilização monetária.

Entretanto, foram decisivas a mobilização social e a eleição de uma minoria atuante de parlamentares constituintes com origem nos movimentos sindical e popular, bem como em outras organizações da sociedade civil, com vínculos com suas bases e comprometidos com as propostas democráticas. Merece destaque o papel cumprido pelos Comitês Pró-Participação Popular na Constituinte, disseminados pelo território nacional, formulando e acompanhando a votação de propostas de interesse da maioria da população brasileira. 
Muitas dessas propostas foram configuradas em emendas populares, asseguradas no artigo 24 do Regimento Interno da Assembleia Nacional Constituinte, subscritas por 30 mil ou mais eleitores brasileiros, em listas organizadas por, no mínimo, três entidades associativas, legalmente constituídas (Brasil, 1987).

Um procedimento utilizado por esses Comitês foi a divulgação, nas bases eleitorais dos deputados e senadores constituintes, de seu posicionamento frente às propostas de interesse democrático e popular. Essa divulgação logrou a mudança de votos de muitos parlamentares, por temerem repercussões negativas em uma futura eleição.

\section{Princípios fundamentais}

Logo em seu artigo $1^{\circ}$, a Constituição Federal de 1988 (Brasil, 1988) define a República Federativa do Brasil como Estado democrático de direito, tendo como fundamentos:

I - a soberania;

II - a cidadania;

III - a dignidade da pessoa humana;

IV - os valores sociais do trabalho e da livre-iniciativa;

$\mathrm{V}$ - o pluralismo político. (Grifos dos autores.)

O parágrafo único desse artigo estabelece que todo poder emana do povo, que o exerce por meio de representantes eleitos ou diretamente, nos termos previstos na Constituição. Esta diretriz abre a perspectiva para a articulação entre a democracia representativa e a participativa, possibilitando a democratização do Estado e legitimando a criação, pelas leis que regulamentaram as políticas públicas, de órgãos deliberativos institucionalizados, com participação da sociedade civil, como conferências e conselhos, além de experiências inovadoras, como a do orçamento participativo, que já obtiveram reconhecimento internacional.

Isso é muito significativo para a sociedade brasileira, considerando-se sua longa tradição política autoritária, com predomínio de um modelo de dominação oligárquico, patrimonialista e burocrático, que resultou i) na marginalização política e social das classes populares, ou sua integração por meio do populismo 
e do clientelismo; ii) na restrição da esfera pública e sua privatização pelas elites; e iii) na "artificialidade" do jogo democrático e da ideologia liberal, causando uma imensa discrepância entre o "país legal" e o "país real" e com obstáculos enormes à construção da cidadania, ao exercício dos direitos e à participação popular autônoma (Santos, 2003).

Em seguida, em seu artigo $3^{\circ}$, a Constituição Federal define os objetivos fundamentais da República Federativa do Brasil:

I - construir uma sociedade livre, justa e solidária;

II - garantir o desenvolvimento nacional;

III - erradicar a pobreza e a marginalização e reduzir as desigualdades sociais e regionais;

IV - promover o bem de todos, sem preconceitos de origem, raça, sexo, cor, idade e quaisquer outras formas de discriminação. (Brasil, 1988, grifos nossos)

Desde os primeiros dispositivos, portanto, a Constituição de 1988 deixa claro que a promoção dos interesses dos trabalhadores e dos demais cidadãos é um traço distintivo da nova Carta, merecendo igual tratamento dado às questões da democracia e do desenvolvimento econômico.

\section{Direitos sociais}

No Título II (Dos Direitos e Garantias Fundamentais), o legislador incluiu os Direitos Sociais (Capítulo II, artigos $6^{\circ}$ a 11), que serão comentados a seguir:

$\mathrm{O}$ artigo $6^{\circ}$ define, de forma ampla, como direitos sociais "a educação, a saúde, o trabalho, o lazer, a segurança, a previdência social, a proteção à maternidade e à infância, a assistência aos desamparados".

No artigo $7^{\circ}$ é que se concentram os direitos dos trabalhadores urbanos e rurais, num total de 34 incisos, alguns dos quais serão comentados a seguir, por representarem efetivos avanços sociais.

Inciso I - relação de emprego protegida contra despedida arbitrária ou sem justa causa, nos termos de lei complementar que preverá indenização compensatória, entre outros direitos. 
Não por acaso, o legislador constituinte inseriu como direito primeiro dos trabalhadores a garantia contra a dispensa imotivada. Ela se justifica em função do reconhecimento da diferença de poder do trabalhador em relação ao empregador na relação de emprego, diferença esta que só é possível superar com a constituição do trabalhador em sujeito coletivo, via sindicato, com atuação efetiva, para o que a garantia contra a despedida arbitrária é precondição.

O dispositivo em tela inspira-se, ainda, na Convenção 158 da Organização Internacional do Trabalho (OIT, 1982), que tem o mesmo objetivo. Essa convenção, embora ratificada pelo Congresso Nacional em setembro de 1992, teve sua vigência suspensa por iniciativa unilateral do governo Fernando Henrique Cardoso, em novembro de 1996, dez meses após ter entrado em vigor no país (Dieese, 1996). Em fevereiro de 2008, em resposta a reivindicação conjunta das centrais sindicais na IV Marcha a Brasília, de dezembro de 2007, o presidente Lula enviou ao Congresso Nacional, mensagem para nova ratificação da Convenção 158 , que tramita no Legislativo. ${ }^{1}$

A lei complementar a que se refere o artigo $7^{\circ}$, Inciso I, até hoje não foi elaborada pelo Parlamento brasileiro. Porém, enquanto a lei complementar não for aprovada, o artigo 10 das Disposições Transitórias da Constituição determina o aumento na multa por despedida sem justa causa, de $10 \%$ para $40 \%$ do saldo do Fundo de Garantia do Tempo de Serviço. Mas, devido aos baixos salários vigentes na economia brasileira e à elevada taxa de rotatividade no emprego por iniciativa do empregador que ocorre no país, saldo e multa acabam sendo de pequena monta, relativizando a proteção pretendida.

Inciso II - seguro-desemprego, em caso de desemprego involuntário.

Outra inovação da Constituição de 1988 foi a garantia de seguro-desemprego, importante elemento do sistema de proteção social dos trabalhadores.

1. A atitude do governo teve repercussão ambígua. Para alguns, bastaria que o presidente Lula editasse um decreto revogando o Decreto n. 2.100/96 assinado pelo ex-presidente Fernando Henrique Cardoso, para que a Convenção, que já havia sido ratificada pelo Congresso em 1982, voltasse a ter eficácia no país. Está tramitando, desde 1997, no Supremo Tribunal Federal, uma Ação Direta de Inconstitucionalidade, movida pela Central Única dos Trabalhadores e pela Confederação Nacional dos Trabalhadores na Agricultura, questionando a legalidade do Decreto n. 2.100/96, com o argumento de que somente o Congresso Nacional poderia denunciar uma convenção por ele ratificada. Até o momento de conclusão deste trabalho, havia o posicionamento de quatro dos onze juízes do STF, com resultado parcial de três votos favoráveis à ADIn e um contrário. 
Apesar de só ter sido regulamentado em 1990, o seguro-desemprego representou enorme avanço social, especialmente diante da escalada das taxas de desemprego ao longo da década de 1990 e nos primeiros anos da década atual (Tabela 1). Embora ainda atinja uma quantidade insuficiente de desempregados, dadas as exigências para acesso a este direito, e se caracterize pela baixa remuneração assegurada e o pequeno período de cobertura, só em 2008 o seguro desemprego atendeu 6,82 milhões de trabalhadores, num valor total de R\$14,1 bilhões (Dieese, 2009).

TABELA 1

Taxa de desemprego total — Região Metropolitana de São Paulo (1985-2009)

\begin{tabular}{|c|c|c|c|}
\hline Ano & $\begin{array}{c}\text { Taxa de desemprego } \\
\text { (em \%) }\end{array}$ & Ano & $\begin{array}{c}\text { Taxa de desemprego } \\
\text { (em \%) }\end{array}$ \\
\hline 1985 & 12,2 & 1998 & 18,2 \\
\hline 1986 & 9,6 & 1999 & 19,3 \\
\hline 1987 & 9,2 & 2000 & 17,6 \\
\hline 1988 & 9,7 & 2001 & 17,6 \\
\hline 1989 & 8,7 & 2002 & 19,0 \\
\hline 1990 & 10,3 & 2003 & 19,9 \\
\hline 1991 & 11,7 & 2004 & 16,9 \\
\hline 1992 & 15,2 & 2005 & 15,8 \\
\hline 1993 & 14,6 & 2006 & 14,8 \\
\hline 1994 & 14,2 & 2007 & 13,4 \\
\hline 1995 & 13,2 & 2008 & 13,8 \\
\hline 1996 & 15,1 & 2009 & \\
\hline 1997 & 16,0 & & \\
\hline
\end{tabular}

Fonte: Pesquisa de Emprego e Desemprego na Região Metropolitana de São Paulo Convênio Dieese/Seade/MTE/FAT (disponível em: <www.dieese.org.br>)

Inciso IV - salário mínimo, fixado em lei, nacionalmente unificado, capaz de atender às suas necessidades vitais básicas e às de sua família com moradia, 
alimentação, educação, saúde, lazer, vestuário, higiene, transporte e Previdência Social, com reajustes periódicos que lhe preservem o poder aquisitivo, sendo vedada sua vinculação para qualquer fim.

Neste inciso, a Constituição reforça o caráter familiar da definição de salário mínimo (como já definido desde 1946) e arrola, de forma ampla, os itens que deve cobrir. A realidade, entretanto, é que o salário mínimo oficial jamais foi suficiente para assegurar esse padrão de vida mínimo, embora já tenha sido fixado bem acima do patamar atual no final da década de 1950. Em valores atuais, de junho de 2010, o salário mínimo mensal médio de 1957 equivalia a $\mathrm{R} \$ 1.381,77$. Mesmo comparado ao valor do primeiro salário mínimo, fixado em julho de 1940, o atual piso de $\mathrm{R} \$ 510,00$ reais equivale a apenas 45,27\% daquele valor. Publicação do Departamento Intersindical de Estatística e Estudos Socioeconômicos (Dieese, 2010) estima o salário mínimo necessário, em junho de 2010, para atender ao dispositivo constitucional, em R $2.092,36$, para uma pequena família de dois adultos e duas crianças.

Entretanto, nos últimos quinze anos, após o Plano Real, o salário mínimo tem sido objeto de recuperação de seu valor, com reajustes superiores às taxas de inflação. Isso resultou numa majoração que mais do que duplicou seu poder aquisitivo. Em 2006, comissão quadripartite (governo, centrais sindicais, confederações patronais e entidades de aposentados) definiu uma política de médio prazo de valorização do salário mínimo, que deve ser reajustado até $2011 \mathrm{em}$ percentual correspondente à variação do Índice Nacional de Preços ao Consumidor, acrescido de aumento real correspondente à variação do Produto Interno Bruto (PIB) ocorrida dois anos antes. Mesmo assim, o alcance do valor assegurado na Constituição, ainda aparece distante no horizonte.

Inciso XI - participação nos lucros, ou resultados, desvinculada da remuneração, e, excepcionalmente, participação na gestão da empresa, conforme definido em lei.

A participação dos trabalhadores nos lucros ou resultados das empresas (PLR) era antiga reivindicação dos trabalhadores, já prevista na Constituição de 1946, mas nunca regulamentada. Reinscrita em 1988, foi regulamentada apenas em dezembro de 1994, no apagar das luzes do governo Itamar Franco, por intermédio de medida provisória (MP). Essa MP foi reeditada inúmeras vezes, até ser convertida na Lei n. 10.101/2000, atualmente em vigor (Brasil, 2000b). A negociação da PLR tem se constituído, desde então, em importante 
item das negociações coletivas entre sindicatos e empresas, num contexto de baixas taxas de inflação e desindexação salarial.

A parte relativa à participação dos trabalhadores na gestão das empresas ainda carece de regulamentação.

Inciso XIII - duração do trabalho normal não superior a oito horas diárias e 44 semanais, facultada a compensação de horários e a redução da jornada, mediante acordo ou convenção coletiva de trabalho.

Outra antiga reivindicação dos trabalhadores era a redução da duração semanal do trabalho para quarenta horas. Nos anos 1980, algumas categorias já haviam alcançado a redução para 44 horas, em acordos coletivos. A Constituição de 1988 veio estender esse direito ao conjunto dos trabalhadores.

É de se observar, entretanto, que as empresas não criaram novos empregos na proporção da redução do tempo de trabalho semanal. Boa parte dessa redução foi compensada com o aumento da produtividade ou do número de horas extras trabalhadas, diante da ampla possibilidade de utilização desse expediente pelas empresas. O movimento sindical desenvolve, hoje, intensa campanha pela redução da jornada para quarenta horas semanais, sem redução salarial e com limitação das horas extras, como forma de melhorar as condições de vida do trabalhador e gerar novos empregos.

Inciso XIV — jornada de seis horas para o trabalho realizado em turnos ininterruptos de revezamento, salvo negociação coletiva.

A redução da jornada para os trabalhadores sujeitos a regime de turnos ininterruptos de revezamento visava garantir compensação a estes trabalhadores pelo desgaste decorrente da alternância de turnos (diurno/noturno) e consequências para sua saúde e convívio social, fartamente comprovados na literatura especializada (Fischer et al., 2003 e Dieese, 1997). Outra consequência imediata dessa medida foi a necessidade de ampliação de quatro para cinco equipes de trabalho por parte das empresas que a utilizam, com reflexos positivos também para o nível de emprego.

A inscrição do termo "salvo negociação coletiva" no Inciso XIV, serviu, num primeiro momento, aos trabalhadores que preferiam manter a jornada de oito horas em troca da ampliação do número de horas de folga, mantendo-se a duração anual do trabalho reduzida, se comparada à duração anual com as seis 
horas diárias. Entretanto, nos anos recentes, foi utilizada pelas empresas como forma de pressionar pelo retorno a tabelas de quatro equipes, diante da ameaça de fixação dos turnos, com prejuízos evidentes para a equipe fixada no turno da noite. Atualmente, poucas empresas ainda adotam as escalas com cinco equipes, cuja extinção vem gerando fortes conflitos e cujo retorno continua na pauta de reivindicação dos sindicatos de trabalhadores. Algumas empresas - inclusive multinacionais - fixaram unilateralmente os turnos nos últimos anos, procedimento que vem sendo questionado pelos sindicatos de trabalhadores, permanecendo o tema como forte elemento de contencioso entre capital e trabalho.

Inciso XVI - remuneração do serviço extraordinário superior, no mínimo em cinquenta por cento à do normal.

O adicional de horas extras foi ampliado em 1988, dos anteriores vinte por cento previstos na CLT, para os atuais cinquenta por cento. Essa medida visava o desestímulo à realização de horas extras, através de seu encarecimento para as empresas. Esse efeito, entretanto, foi insuficiente para reduzir o número de horas extras trabalhadas, por ter sido adotado sem que fosse reduzido o número total mensal de horas extras permitido (Calvete, 2006). Mas em acordos e convenções coletivas de trabalho a majoração desse percentual tem sido negociada com algum sucesso.

Inciso XVII - gozo de férias anuais remuneradas com, pelo menos, um terço a mais do que o salário normal.

Esse adicional de um terço sobre o valor das férias inspirou-se em cláusulas de acordos e convenções coletivas de algumas categorias, que asseguravam o que se convencionou chamar de "retorno de férias". Esse adicional permite ao trabalhador a destinação de parte de sua remuneração para o efetivo gozo das férias.

Inciso XVIII - licença à gestante, sem prejuízo do emprego e do salário, com a duração de 120 dias.

Outra ampliação de direitos, realizada pela Constituição Federal de 1988, refere-se à licença-maternidade, que passou de noventa para 120 dias, pagos pela Previdência Social, para que não houvesse discriminação do trabalho feminino pelas empresas. Essa licença visa possibilitar maior dedicação da mãe à criança num período crítico do seu desenvolvimento, garantindo, inclusive, melhores condições para a prática do aleitamento. 
Em setembro de 2008, o Congresso Nacional aprovou a Lei n. 11.770, prevendo a extensão da licença-maternidade para seis meses, por iniciativa opcional das empresas, que passam a poder deduzir esse custo extra do recolhimento de seu imposto de renda (Brasil, 2008b).

Inciso XIX - licença-paternidade, nos termos fixados em lei.

A criação desse direito, embora restrito, veio incentivar o aprofundamento da relação pai-filhos e sinaliza no sentido de uma melhor distribuição das tarefas domésticas no pós-parto, contribuindo para o aperfeiçoamento das relações de gênero.

A lei regulamentadora ainda não foi criada, valendo a regra das Disposições Transitórias da Constituição, que prevê um período de apenas cinco dias corridos, contados do nascimento da criança. Nesse sentido, existe ainda um longo caminho a ser percorrido no futuro, para, quem sabe, podermos usufruir de um período bem mais extenso, que amplie as vantagens da licença-paternidade, diminuindo, assim, o risco de discriminação das mulheres no mercado de trabalho. ${ }^{2}$

Inciso XXVII — proteção em face da automação, na forma da lei.

A proteção do trabalhador em face da introdução de inovações tecnológicas por parte das empresas ainda continua dependente de regulamentação. Sua importância é evidente, como atestam os dados sobre a redução do emprego bancário no Brasil nos anos 1990, de um total de aproximadamente 1 milhão de trabalhadores para o contingente atual de cerca de 400 mil bancários. Essa redução decorreu, em boa medida, da introdução de inovações tecnológicas pelos bancos, sem qualquer negociação ou compensação aos trabalhadores.

Inciso XXIX - ação, quanto a créditos resultantes das relações de trabalho, com prazo prescricional de:

a) cinco anos para o trabalhador urbano, até o limite de dois anos após a extinção do contrato;

b) até dois anos após a extinção do contrato, para o trabalhador rural.

2. Na Suécia, a licença quando do nascimento de um filho, é de 450 dias (quinze meses), que podem ser compartilhados (metade e metade) por pai e mãe e usufruídos em tempo integral, em meio expediente ou durante $1 / 4$ da jornada (Faria, 2002). 
Este inciso ampliou o prazo de prescrição de direitos do trabalhador urbano, que era de dois anos, para cinco anos, favorecendo a recuperação de direitos lesados pelo empregador.

Inciso XXXIV, parágrafo único — são assegurados à categoria dos trabalhadores domésticos, os direitos previstos nos incisos IV, VI, VIII, XV, XVII, XIII, XIX, XXI e XXIV, bem como a sua integração à Previdência Social.

Este parágrafo amplia significativamente os direitos dos empregados domésticos, em relação ao status anterior. ${ }^{3}$ Mesmo assim, não lhes foram estendidos importantes direitos, como a limitação da jornada de trabalho, adicionais de hora extra e noturno, salário-família, entre outros. O significado desta ampliação de direitos pode ser dimensionado quando se constata o peso dessa categoria profissional entre os trabalhadores brasileiros e sua composição predominantemente feminina e de raça negra.

A liberdade de organização sindical

O artigo $8^{\circ}$ trata da garantia de organização sindical. Diz o artigo:

Artigo $8^{\circ}$ - É livre a associação profissional ou sindical, observado o seguinte:

I - a lei não poderá exigir autorização do Estado para a fundação de sindicato, ressalvado o registro no órgão competente, vedadas ao poder público a interferência e a intervenção na organização sindical;

II - é vedada a criação de mais de uma organização sindical, em qualquer grau, representativa de categoria profissional ou econômica, na mesma base territorial, que será definida pelos trabalhadores ou empregadores interessados, não podendo ser inferior à área de um município;

3. A Lei n. 5,859/72, que regulamentou a profissão de empregado doméstico, previa apenas a necessidade de registro em carteira de trabalho, férias anuais de vinte dias úteis e acesso aos benefícios e serviços da Lei Orgânica da Previdência Social (Brasil, 1972). Posteriormente à Constituição de 1988, outras leis ampliaram direitos do empregado doméstico, como a Lei n. 10.208/2001 — que estendeu a eles o FGTS (em caráter opcional) e o seguro-desemprego (Brasil, 2001) e a Lei n. 11.324/2006, que estendeu a estabilidade da gestante desde a confirmação da gravidez e até cinco meses após o parto, definiu as férias de trinta dias corridos com adicional de um terço, além de precisar outros artigos da Lei n. 5.859/72 (Brasil, 2006a). 
III - ao sindicato cabe a defesa dos direitos e interesses coletivos ou individuais da categoria, inclusive em questões judiciais ou administrativas;

IV - a assembleia geral fixará a contribuição que, em se tratando de categoria profissional, será descontada em folha, para custeio do sistema confederativo da representação sindical respectiva, independentemente da contribuição prevista em lei:

$\mathrm{V}$ — ninguém será obrigado a filiar-se ou a manter-se filiado a sindicato;

VI - é obrigatória a participação dos sindicatos nas negociações coletivas de trabalho;

VII - o aposentado filiado tem direito a votar e ser votado nas organizações sindicais;

VIII — é vedada a dispensa do empregado sindicalizado a partir do registro da candidatura a cargo de direção ou representação sindical e, se eleito, ainda que suplente, até um ano após o final do mandato, salvo se cometer falta grave nos termos da lei;

Parágrafo único - As disposições deste artigo aplicam-se à organização de sindicatos rurais e de colônias de pescadores, atendidas as condições que a lei estabelecer.

Este artigo $8^{\circ}$ apresenta evidentes avanços, ao proibir qualquer intervenção do Estado na vida sindical, ao contrário do que ocorria até então. Define o sindicato como organização de direito privado - e não mais como órgão de colaboração com o poder público - e exige a presença do sindicato em qualquer processo de negociação coletiva. A liberdade sindical, entretanto, foi restringida no tocante à forma de organização sindical, que prevê a compulsoriedade da organização unicista por categoria, eliminando a possibilidade de os trabalhadores decidirem, eles mesmos, entre uma estrutura unicista ou pluralista, como ocorre na maioria dos países desenvolvidos, signatários da Convenção 87 da Organização Internacional do Trabalho (OIT, 1948). Essa restrição reflete a própria ausência de consenso no interior do movimento sindical patronal e de trabalhadores, a respeito do grau de liberdade almejado e configura-se como uma das antinomias presentes no texto constitucional.

A Constituição de 1988 estendeu, também, aos servidores públicos o direito de sindicalização, até então proibida, conforme o artigo 37, Inciso VI: 
Artigo 37 - Inciso VI — é garantido ao servidor público civil o direito à livre associação sindical.

O legislador não previu, porém, o direito de negociação coletiva aos servidores públicos, gerando uma situação paradoxal, onde o trabalhador tem o direito de se constituir em sindicato, mas este não tem poder negocial, que é a sua própria razão de ser.

0 direito de greve

Um dos maiores avanços inscritos na Constituição de 1988 refere-se ao direito de greve, previsto de forma abrangente no artigo $9^{\circ}$ :

Artigo $9^{\circ}$ - É assegurado o direito de greve, competindo aos trabalhadores decidir sobre a oportunidade de exercê-lo e sobre os interesses que devam por meio dele defender.

$\S 1^{\circ}$ - A lei definirá os serviços ou atividades essenciais e disporá sobre $\mathrm{o}$ atendimento das necessidades inadiáveis da comunidade.

$\S 2^{\circ}$ - Os abusos cometidos sujeitam os responsáveis às penas da lei.

A história do país revela que o direito de greve foi sempre restringido pela legislação, mesmo quando assegurado constitucionalmente. A começar pelo Código Penal de 1890 (art. 205 e 206), que previa pena de prisão e multa em caso greve, passando pelo Decreto n. 21.396, de 1932 e pela Lei n. 38, de 1935. A inscrição da greve como tema constitucional ocorreria apenas na Constituição de 1937, outorgada por Getúlio Vargas sob a ditadura do Estado Novo, que considerava a greve "recurso antissocial" e, por isso mesmo, proibida (Brasil, 1978). Com o fim do Estado Novo e a redemocratização do país, a nova Constituição, promulgada em setembro de 1946, assegurava o exercício do direito de greve, mas remetia sua regulamentação à lei ordinária. Naquela ocasião, entretanto, o Supremo Tribunal Federal considerou válidos os dispositivos do Decreto-lei n. 9.070 (Brasil, 1946), de março daquele ano, como sendo compatíveis com o novo preceito constitucional, embora anteriores à nova Constitui- 
ção e malgrado restringissem fortemente o exercício do direito de greve ${ }^{4}$. Em junho de 1964, após o golpe militar, o Decreto-lei n. 9.070 foi substituído pela Lei n. 4.330 (Brasil, 1964), mais conhecida como "lei antigreve", tamanhas as restrições que impunha ao exercício desse direito fundamental do trabalhador. Essa lei, complementada em 1978 pelo Decreto-lei n. 1.632 (sobre greve em serviços essenciais), vigorou até outubro de 1988, quando foi revogada pela nova Constituição. Em todo esse período, portanto, para usar uma metáfora já de domínio público, a regulamentação do direito de greve transformou o direito em delito.

Como visto, a Constituição de 1988 assegurou de forma ampla o direito de greve. Mas, sob o pretexto de regulamentar o parágrafo $1^{\circ}$ do artigo $9^{\circ}$, o governo Sarney (1985-1989) editou uma Medida Provisória (MP-50), logo em abril de 1989, no bojo de um surto grevista contra as medidas do Plano Verão de estabilização, que confiscava os salários dos trabalhadores. (Brasil, 1989a). As greves por categoria culminaram com a realização da greve geral de 14 e 15 de março de 1989, pouco antes da edição da MP-50. Essa MP, reeditada em 26 de maio, seria posteriormente convertida pelo Congresso Nacional na Lei $\mathrm{n}$. 7.783, de 28 de junho de 1989, ainda hoje em vigor (Brasil, 1989b). Essa lei restringe claramente o direito de greve em todos os setores - em vez de se deter na identificação dos serviços ou atividades essenciais e na garantia do atendimento das necessidades essenciais da comunidade, em caso de greve. Além de exigir uma série de procedimentos para que a greve se inicie - em claro confronto com o caput do artigo $9^{\circ}$ da Constituição de 1988 - a Lei n. 7.783 dá ao procurador regional do Trabalho a prerrogativa de instaurar, imediatamente após a deflagração da greve, o dissídio coletivo na Justiça do Trabalho e a greve, mesmo se for considerada legal (não abusiva, nos termos atuais), deve ser interrompida após a decisão do tribunal sobre o mérito das reivindicações, sob pena de se tornar abusiva a partir daí, sujeitando os trabalhadores e seus sindicatos a uma série de penalizações. Mesmo que a decisão de mérito do tribunal contrarie totalmente os pleitos que suscitaram a eclosão da greve.

A revogação da Lei n. 7.783/89 é condição necessária para restabelecer o direito de greve, da forma como definido pelo legislador constituinte.

4. Esse procedimento do STF denomina-se "recepção de norma jurídica preexistente". 
A Constituição de 1988 estendeu, ainda, o direito de greve aos servidores públicos, no seu artigo 37 :

Artigo 37 - Inciso VII - o direito de greve será exercido nos termos e nos limites definidos em lei complementar. ${ }^{5}$

A lei específica sobre o direito de greve no serviço público ainda não foi elaborada. Para evitar esse vácuo jurídico, o Supremo Tribunal Federal estendeu provisoriamente aos servidores públicos, em 2007, as regras previstas na Lei n. $7.783 / 89$ para os trabalhadores da iniciativa privada.

A representação dos trabalhadores nos locais de trabalho

Por fim, o artigo 11 da Constituição de 1988 prevê a eleição de um representante dos trabalhadores nas empresas com mais de duzentos empregados:

Artigo 11 - Nas empresas de mais de duzentos empregados, é assegurada a eleição de um representante destes com a finalidade exclusiva de promoverlhes o entendimento direto com os empregadores.

Este tema, tão caro ao sindicalismo, acabou tratado de forma evidentemente insuficiente na Constituição de 1988. Mesmo assim, o entendimento prevalecente é o de que o Artigo 11 ainda depende de regulamentação, o que não ocorreu até hoje.

Juntamente com a garantia contra a dispensa imotivada e o direito amplo de greve, a representação dos trabalhadores nos locais de trabalho forma o tripé que asseguraria um maior equilíbrio de forças entre o capital e o trabalho na relação de emprego. Essa tarefa continua, pois, em aberto. Foi tratada no âmbito do Fórum Nacional do Trabalho - espaço tripartite de negociação de modificações no Sistema Brasileiro de Relações de Trabalho - , proposto pelo governo Lula em 2003, e consta do Anteprojeto de Lei de Relações Sindicais que resultou do consenso obtido no Fórum, mas que ainda não foi enviado ao Congresso Nacional, por exigir prévia mudança constitucional dos artigos $8^{\circ}$, 11, 37 e 114. Essa mudança foi proposta pela Emenda Constitucional 369, cuja tramitação está paralisada no Congresso desde abril de 2005 (Brasil, 2005a).

5. Alterado de "lei complementar" para "lei específica" pela Emenda Constitucional n 19 (Brasil, 1998a). 


\section{Seguridade social}

Um avanço expressivo, obtido na Constituição Federal de 1988, foi a adoção do conceito de Seguridade Social, definida no artigo 194 como um conjunto integrado de ações de iniciativa dos poderes públicos e da sociedade, destinadas a assegurar os direitos relativos à saúde, à previdência e à assistência social. Foram estabelecidos, ainda, os objetivos que devem ser alcançados pelo poder público, na sua competência de organizar a seguridade social: a universalidade da cobertura e do atendimento, a uniformidade e equivalência dos benefícios e serviços às populações urbanas e rurais, a seletividade e distributividade na prestação dos benefícios e serviços, a irredutibilidade do valor dos benefícios, a equidade na forma de participação no custeio, a diversidade da base de financiamento e o caráter democrático e descentralizado da gestão administrativa, ${ }^{6}$ com a participação da comunidade, em especial de trabalhadores, empresários e aposentados.

O estabelecimento de tais objetivos e das posteriores diretrizes da saúde, previdência e assistência social significa, no plano jurídico, um avanço no campo da cidadania no Brasil, e evidencia o propósito de correção de situações injustas existentes até aquele momento, como, por exemplo, a perda do poder aquisitivo das aposentadorias e o tratamento desigual entre trabalhadores urbanos e rurais.

Ressalte-se, no entanto, que a adoção do conceito de seguridade social deu-se, no Brasil, com muito atraso. A Declaração Universal dos Direitos do Homem, firmada em 1948, no artigo 85, já estabelecia o direito à seguridade social como direito de todos os povos:

Todo o homem tem direito a um padrão de vida capaz de assegurar a si e a sua família saúde e bem-estar, inclusive alimentação, vestuário, habitação, cuidados médicos, os serviços sociais indispensáveis, o direito à seguridade social no caso de desemprego, doença, invalidez, viuvez, velhice, ou outros casos de perda dos meios de subsistência em circunstâncias fora de seu controle. (ONU, 1948)

6. A Emenda Constitucional n. 20/98 (Brasil, 1998b) deu nova redação ao inciso VII deste artigo: "Caráter democrático e descentralizado da administração, mediante gestão quadripartite, com participação dos trabalhadores, dos empregadores, dos aposentados e do governo nos órgãos colegiados". 
A Convenção 102 da Organização Internacional do Trabalho, adotada em Genebra em 28 de junho de 1952 e ratificada pelo Brasil somente em setembro de 2008, estabelece que

seguridade social é a proteção que a sociedade proporciona a seus membros mediante uma série de medidas públicas contra as privações econômicas e sociais que de outra forma derivariam no desaparecimento ou em forte redução de sua subsistência como consequência de enfermidade, maternidade, acidente de trabalho ou enfermidade profissional, desemprego, invalidez, velhice e morte e também a proteção em forma de assistência médica e de ajuda às famílias com filhos. (OIT, 1952)

Outra conquista importante da Constituição Federal de 1988 foi a definição, no artigo 195, das fontes de financiamento da seguridade social, coerente com seus objetivos, expressos no artigo 194, respectivamente nos incisos V e VI, de equidade na forma de participação no custeio e de diversidade da base de financiamento.

Segundo o artigo 195, esse financiamento será feito por toda a sociedade, de forma direta e indireta, nos termos da lei, mediante recursos dos orçamentos da União, dos estados, do Distrito Federal e dos municípios, bem como das contribuições sociais dos empregadores, incidente sobre a folha de salários, o faturamento e o lucro; dos trabalhadores; e sobre a receita de concursos de prognósticos. $^{7}$

A definição de fontes alternativas para o financiamento do sistema de proteção social tem sido adotada em diversos países, uma vez que o capitalismo, na atualidade, tem trazido redução de postos de trabalho e períodos recessivos, sendo temerário que esse sistema dependa exclusivamente de contribuições de empregadores e trabalhadores.

Outro avanço significativo, em termos da Seguridade Social, foi o estabelecimento, no parágrafo $5^{\circ}$ do artigo 165 , de que a lei orçamentária anual compreenderá o orçamento fiscal, o orçamento de investimento das empresas em que a União, direta ou indiretamente, detenha a maioria do capital social com direito a voto, e o orçamento da seguridade social (grifo dos autores).

7. As emendas constitucionais ns. 20/98, n. 42/03 e 47/05 deram novas redações aos incisos I, II, III e IV do artigo 195 da CF/88, especificando melhor as fontes de financiamento da seguridade social. 
Essa especificidade do orçamento da seguridade social visava impedir que seus recursos fossem utilizados para outras finalidades, o que sempre caracterizou a história da Previdência Social brasileira. Entretanto, este Orçamento da Seguridade Social nunca foi elaborado. Os governos vêm divulgando apenas o Orçamento de Investimento das Empresas Estatais e o Orçamento Fiscal e da Seguridade Social. Este último, ao agregar as respectivas receitas e gastos, dificulta a análise em separado do Orçamento Fiscal e da Seguridade Social (Dieese, 2007).

Inúmeros avanços podem ser identificados a partir de uma análise específica das políticas que integram a Seguridade Social. No âmbito da saúde e da assistência social, podem ser citados, entre outros, a descentralização e a participação social, a universalização do acesso à saúde; o estabelecimento da assistência social, pela primeira vez, como política pública, no mesmo patamar da saúde e da previdência; a criação, no âmbito da assistência social, do Benefício de Prestação Continuada mensal, no valor de um salário mínimo, para idosos e portadores de deficiência que comprovem não possuir meios de prover a própria manutenção ou de tê-la provida por sua família. No âmbito da Previdência, podem ser citadas, entre outras, as seguintes conquistas: a extensão aos trabalhadores rurais de benefícios antes restritos aos urbanos; a redução da idade, em cinco anos, para aposentadorias rurais; o piso de um salário mínimo para todos os benefícios; o cálculo dos benefícios com base nos últimos 36 meses de contribuição, corrigidos monetariamente mês a mês, a pensão por morte para homens, e o $13^{\circ}$ benefício para aposentados e pensionistas tendo por base o valor dos proventos do mês de dezembro de cada ano.

Logo após a promulgação da Constituição Federal de 1988, no entanto, houve uma mudança na correlação de forças no país e a reorganização dos setores dominantes, que sempre se opuseram à ampliação dos direitos sociais no Brasil, obstaculizando a implantação de direitos consagrados pela Carta Magna. Esta conjuntura se articulou com a conjuntura internacional, no contexto da crise do capitalismo e de sua reestruturação produtiva, e com o receituário dos centros hegemônicos do capital financeiro e de seus representantes institucionais - o Fundo Monetário Internacional, o Banco Mundial e o Banco Interamericano de Desenvolvimento. As recomendações para os chamados países em desenvolvimento, como o Brasil, eram de desregulamentação da economia e de busca do Estado mínimo, com privatizações de empresas e serviços públicos e redução de investimentos nas áreas sociais. 
Nesse contexto, surgem as propostas de alteração da Constituição, o que estava previsto no artigo $3^{\circ}$ do Ato das Disposições Constitucionais Transitórias, que estabelecia uma revisão constitucional cinco anos após sua promulgação. A Seguridade Social, e especificamente a Previdência, foram alvo de debates e propostas de reforma, que se concretizaram com a Emenda Constitucional n. 20, de 1998, na gestão do presidente Fernando Henrique Cardoso; e com as Emendas Constitucionais ns. 43, de 2003, e 47, de 2005, na gestão do presidente Luiz Inácio Lula da Silva (Brasil, 1998b, 2003 e 2005b).

Não é propósito deste trabalho aprofundar a análise dessas reformas, salientando-se, no entanto, que elas apresentam distinções em termos de diretrizes políticas e de efeitos. Há que se destacar que a reforma, na gestão do presidente Fernando Henrique Cardoso, desconstruiu vários avanços assegurados na Constituição de 1988, e que a reforma, na gestão do presidente Lula, manteve alguns desses retrocessos.

Entre eles, pode-se citar a introdução, no artigo 201, do princípio do “equilíbrio financeiro e atuarial' na organização da previdência pública. Se imposto de forma rígida, este princípio pode limitar o objetivo redistributivo da seguridade, entrando em contradição com a concepção dos benefícios da seguridade como direitos de cidadania.

Outro retrocesso decorre da mudança, para acesso à aposentadoria, do critério de tempo de serviço para tempo de contribuição. Ainda outra alteração significativa, efetuada por meio da Lei n. 9.876/99 (Brasil, 1999), ocorreu na fórmula de cálculo das aposentadorias do setor privado, com a extensão do tempo considerado para calcular a média dos salários de contribuição, que define o valor do benefício, e pela criação do Fator Previdenciário, que reduz o valor do benefício, caso o trabalhador seja jovem ou tenha pouco tempo de contribuição. ${ }^{8}$

Concretamente, essas reformas basearam-se e reforçaram o mito, cotidianamente difundido, da crise financeira da Previdência Social. Essa visão desconsidera as fontes de financiamento da seguridade social como um todo. Em estudo recente, Gentil (2007) mostra que se as fontes de financiamento da Se-

8. Em junho de 2010, foi aprovada no Congresso Nacional a extinção do fator previdenciário. O presidente Lula, entretanto, vetou essa matéria e seu veto não foi ainda submetido à apreciação do Congresso, até o momento de fechamento deste artigo. 
guridade Social forem destinadas exclusivamente para seu custeio, deixando de financiar os rombos do orçamento fiscal; o sistema de seguridade social mostra-se superavitário. Essa autora conclui que o desequilíbrio orçamentário está no orçamento fiscal e não no da seguridade ou da previdência; que a seguridade não recebe recursos do orçamento fiscal; ao contrário, parte substancialmente elevada de seus recursos financia o orçamento fiscal, sobretudo para compor o superávit primário para pagamento de juros da dívida pública e para fazer frente aos encargos previdenciários da União com seus servidores. ${ }^{9}$

Também a Lei Complementar n. 101/2000 (Brasil, 2000a), conhecida como Lei de Responsabilidade Fiscal, contraria a concepção de seguridade social e sua forma de financiamento previstas na Constituição Federal, ao restringir os recursos do então criado Fundo do Regime Geral da Previdência Social basicamente às contribuições de trabalhadores e sobre as folhas de salários das empresas (Inciso III do art. 68), legitimando a ideia de que a alocação de recursos de outras contribuições constitui transferências do Tesouro (Dieese, 2007).

Há uma clara contradição entre os princípios constitucionais da seguridade social e suas fontes de financiamento e artigos da própria Constituição ou de legislação infraconstitucional, que contrariam esses princípios.

De outro lado, verificaram-se também alguns avanços em termos de inclusão previdenciária nos últimos anos, previstos nas Emendas Constitucionais ns. 43 e 47 e consubstanciados na Lei Complementar n. 123/2006, conhecida como Lei Geral das Micro e Pequenas Empresas (Brasil, 2006b). Trata-se da redução da alíquota de contribuição de $20 \%$ para $11 \%$ para o contribuinte individual (autônomo) que não seja prestador de serviços a empresas ou cooperativas e ao contribuinte individual (empresário ou sócio de empresa) com receita bruta anual de até R \$36.000,00 e o contribuinte facultativo. Quem opta pela alíquota simplificada tem direito a todos os benefícios previdenciários, exceto a aposentadoria por tempo de contribuição.

Estudos provam que os benefícios previdenciários e assistenciais são responsáveis pela diminuição da pobreza no Brasil (França, 2009) e Brasil (2008d) e que o nível de universalização do acesso à saúde no Brasil é o maior do mun-

9. Desde 1994, parte considerável (20\%) dos recursos vinculados constitucionalmente, entre eles os da Seguridade Social, são retidos pela União para livre aplicação em outras rubricas, o que tem resultado na redução dos gastos nas áreas sociais. É a chamada Desvinculação das Receitas Orçamentárias — DRU, prevista em sucessivas Emendas Constitucionais. 
do. Além disso, prosseguem, com os instrumentos criados a partir da Constituição de 1988, as iniciativas de democratização do Estado, nos níveis federal, estadual e municipal.

Mesmo com as investidas de desconstrução, os avanços assegurados pela Constituição de 1988 são relevantes se se compara o sistema de proteção social no Brasil com o de outros países da América Latina. E as propostas do neoliberalismo, de Estado mínimo e privatização dos serviços públicos, não foram implementadas de forma tão radical no Brasil como em outros países dessa região, devido à ação de parlamentares comprometidos com as causas sociais e à pressão de setores da sociedade, que trabalham na defesa da seguridade social.

\section{Considerações finais}

A batalha em torno dos direitos sociais, travada inicialmente no Congresso Constituinte em 1987-88, segue tendo desdobramentos até os dias atuais. Em 2003, o governo Lula convocou o Fórum Nacional do Trabalho (FNT), de caráter tripartite, com o objetivo de discutir mudanças profundas na estrutura sindical e, posteriormente, na legislação trabalhista. O FNT concluiu a primeira parte desse trabalho em 2005, quando foi enviada ao Congresso Nacional uma Proposta de Emenda Constitucional (PEC 369), alterando os artigos 8 $8^{\circ}, 11$, 37 e 114 da Constituição Federal, que tratam respectivamente da estrutura sindical, da representação dos trabalhadores nas empresas, dos direitos do servidor público e do papel da Justiça do Trabalho (Brasil, 2005a). Juntamente com essa PEC, foi elaborado, também, um amplo Anteprojeto de Relações Sindicais, previsto para seguir para o Congresso Nacional após a votação da PEC 369, alterando profundamente as condições de criação e sustentação de sindicatos, o direito de greve e as regras da negociação coletiva e de solução de conflitos coletivos de trabalho. Essas iniciativas, contudo, continuam com tramitação paralisada no Legislativo. Por um lado, o FNT não logrou incluir todas as correntes políticas presentes no movimento sindical, algumas das quais se reuniram num fórum alternativo, o Fórum Sindical dos Trabalhadores (FST), que produziu outra proposta, mantendo basicamente os atuais marcos da estrutura sindical e do processo de solução de conflitos coletivos. Além disso, as próprias Centrais Sindicais que participaram do Fórum tiveram dificuldade de enraizar 
as discussões sobre as mudanças nas suas bases sindicais, muitas das quais não se identificaram plenamente com as propostas. E, finalmente, o encaminhamento da PEC 369 ao Congresso Nacional coincidiu com a eclosão de forte crise política no país, conhecida como o episódio do "Mensalão", que alterou radicalmente a agenda política nacional. Essa discussão continua, portanto, inconclusa e sem previsão de continuidade.

Quanto ao tema da Seguridade Social e, em especial, da Previdência Social, em 2007, o governo Lula convocou o Fórum Nacional da Previdência Social, de composição tripartite, formado por representantes dos trabalhadores (ativos, aposentados e pensionistas), empregadores e governo, que desenvolveu seus trabalhos de fevereiro a outubro daquele ano. Sua finalidade foi discutir o aperfeiçoamento e a sustentabilidade dos regimes de Previdência Social e sua coordenação com as políticas de assistência social, além de subsidiar a elaboração de proposições legislativas e normas infralegais pertinentes.

O Fórum se constituiu num espaço de explicitação dos vários diagnósticos e propostas existentes na sociedade brasileira em relação à Previdência Social. Não logrou, entretanto, obter consenso em todos os temas tratados. Do ponto de vista dos trabalhadores, essa falta de consenso representou, pelo menos, a garantia de que não haveria retrocessos.

Outra iniciativa de mudanças no financiamento da Seguridade Social ocorreu em 2008, com o envio ao Congresso Nacional, pelo governo federal, de uma Proposta de Emenda Constitucional (PEC 233/08) dispondo sobre a Reforma Tributária, que ainda se encontra em tramitação. Na avaliação de dezenas de entidades da sociedade civil brasileira que recentemente se manifestaram ao Congresso Nacional, a referida PEC, a despeito de alguns avanços em vários aspectos do Sistema Tributário Nacional, traz graves consequências ao financiamento das políticas sociais no país. Segundo essa análise, as mudanças propostas comprometem substancialmente as fontes exclusivas de financiamento da Seguridade Social (Previdência, Saúde e Assistência Social), da Educação e do Trabalho (Brasil, 2008c).

Do que foi exposto neste trabalho, fica a certeza de que os avanços constitucionais no campo dos direitos sociais foram e continuam sendo um passo de extrema relevância para que a sociedade brasileira continue seu caminho rumo à superação das graves desigualdades sociais e à construção da cidadania. No entanto, é imperioso constatar que esses avanços continuam em disputa na 
sociedade brasileira e é fundamental que os cidadãos os conheçam e continuem lutando por sua permanência e aprimoramento no plano jurídico e na vida real.

Artigo recebido em jul./2010 - Aprovado em dez./2010

\section{Referências bibliográficas}

BRASIL. Decreto-lei n. 9.070, de 15 de março de 1946. Diário Oficial da União, Rio de Janeiro, 16 mar. 1946.

. Lei n. 4.330, de $1^{\circ}$ de junho de 1964. Diário Oficial da União, Brasília, 2 jun. 1964.

$12 \mathrm{dez} .1972$.

Lei n. 5.859, de 11 de dezembro de 1972. Diário Oficial da União, Brasília,

. Constituições brasileiras - Império e República. São Paulo: Sugestões Literárias, 1978.

. Resolução n. 2 de 1987. Dispõe sobre o Regimento Interno da Assembleia Nacional Constituinte. Diário Oficial da União, Brasília, ano I, n. 33, 25 mar. 1987.

. Constituição da República Federativa do Brasil. Brasília: Senado Federal, 1988.

. Medida Provisória n. 50, de 27 de abril de 1989. Diário Oficial da União, Brasília, 28 abr. 1989a. jun. 1989b.

. Lei n. 7.783, de 28 de junho de 1989. Diário Oficial da União, Brasília, 29 de

. Emenda Constitucional n. 19, de 4 de junho de 1998. Diário Oficial da União, Brasília, 5 jun. 1998a.

. Emenda Constitucional n. 20, de 15 de dezembro de 1998. Diário Oficial da União, Brasília, 16 dez. 1998 b.

lia, 29 nov. 1999.

Lei n. 9.876/99, de 26 de novembro de 1999. Diário Oficial da União, Brasí-

. Lei Complementar n. 101, de 4 de maio de 2000. Diário Oficial da União, Brasília, 5 maio 2000a.

. Lei n. 10.101, de 19 de dezembro de 2000. Diário Oficial da União, Brasília, 20 dez. 2000 b. 
BRASIL. Lei n. 10.208, de 23 de março de 2001. Diário Oficial da União, Brasília, 24 mar. 2001.

. Emenda Constitucional n. 42, de 19 de dezembro de 1998. Diário Oficial da União, Brasília, 31 dez. 2003.

. Ministério do Trabalho. Fórum Nacional do Trabalho. Proposta de Emenda Constitucional n. 369 e Anteprojeto de lei de Relações Sindicais. Brasília: Ministério do Trabalho, 14 fev. 2005a.

. Emenda Constitucional n. 47, de 5 de julho de 2005. Diário Oficial da União, Brasília, 6 jul. 2005 b. jul. 2006a.

. Lei n. 11.324, de 19 de julho de 2006. Diário Oficial da União, Brasília, 20

. Lei Complementar n. 123, de 14 de dezembro de 2006. Diário Oficial da União, Brasília, 15 dez. 2006b.

. Constituição da República Federativa do Brasil (com as alterações adotadas pelas Emendas Constitucionais n. 1/1992 a 56/2007 e pelas Emendas Constitucionais de Revisão n. 1 a 6/1994. 29. ed. Brasília: Câmara dos Deputados, 2008a.

. Proposta de Emenda Constitucional n. 233/2008. Altera o Sistema Tributário Nacional e dá outras providências. Brasília, 28 de fevereiro de 2008b.

10 set. 2008 c.

. Lei n. 11.770, de 9 de setembro de 2008. Diário Oficial da União, Brasília, de

. Ministério do Planejamento e Orçamento Geral. Instituto de Pesquisa Econômica Aplicada. Assistência social e segurança alimentar e nutricional. Boletins Ipea. Políticas Sociais - Acompanhamento e Análise, n. 16, nov. 2008d.

CALVETE, Cássio da Silva. Redução da jornada de trabalho: uma análise econômica para o Brasil. Tese (Doutorado) — Unicamp, Campinas, 2006.

DIEESE. Anuário dos Trabalhadores. 10. ed. São Paulo: Dieese, 2009.

. A situação do trabalho no Brasil. São Paulo: Dieese, 2001.

. Cesta básica nacional de junho de 2010. Disponível em: <www.dieese.org.br>. Acesso em: 10 jul. 2010.

. Jornada reduzida para turnos de revezamento. Boletim Dieese, São Paulo, n. 197, ago. 1997.

. Previdência Social brasileira: concepção constitucional e tentativas de desconstrução. Nota Técnica n. 51, set. 2007. 
DIEESE. Proteção contra demissão sob ameaça do governo. Boletim Dieese, São Paulo, n. 188 , nov. 1996.

DUARTE, Adriana. O processo de reforma da Previdência Social pública brasileira: um novo padrão de regulação social do Estado? Serviço Social \& Sociedade, São Paulo, ano XXIV, n. 73, p. 120-141, mar. 2003.

FARIA, Carlos Aurélio Pimenta de. Entre marido e mulher, o Estado mete a colher: reconfigurando a divisão do trabalho doméstico na Suécia. Revista Brasileira de Ciências Sociais, v. 17, n. 48, fev. 2002.

FRANÇA, Álvaro Sólon de. Previdência - 86 anos de solidariedade e justiça social. Disponível em: <http://www.diap.org.br/index.php/artigos/7305-previdencia-86-anosde-solidariedade-e-justiça-social >. Acesso em: 3 fev. 2009.

FISCHER, Frida Marina; MORENO, Cláudia Roberta de C.; ROTEMBERG, Lúcia (Orgs.). Trabalho em turnos e noturno na sociedade 24 horas. São Paulo: Ateneu, 2003.

GENTIL, Denise Lobato. A política fiscal e a falsa crise do sistema de seguridade social no Brasil: análise financeira do período recente. In: SICSÚ, João (Org.). Arrecadação (de onde vem?) e gastos públicos (para onde vão?). São Paulo: Boitempo, 2007. p. 29-35.

OIT — ORGANIZAÇÃO INTERNACIONAL DO TRABALHO, Convenção 87. Genebra, 1948. . Convenção 102. Genebra, 1952. . Convenção 158. Genebra, 1982.

ONU — ORGANIZAÇÃO DAS NACÕES UNIDAS, Declaração Universal dos Direitos Humanos. Nova York, 1948.

SANTOS, Boaventura de Sousa. Orçamento participativo em Porto Alegre: para uma democracia redistributiva. In: SANTOS, Boaventura de Sousa (Org.). Democratizar a democracia: os caminhos da democracia participativa. 2. ed. Rio de Janeiro: Civilização Brasileira, 2003.

SANTOS, Wanderley Guilherme dos. Cidadania e justiça: a política social na ordem brasileira. 3. ed. Rio de Janeiro: Campus, 1994.

SILVA, Maria Lúcia Lopes da. Previdência Social — um direito conquistado: resgate histórico, quadro atual e propostas de mudanças. 2. ed. Brasília: Ed. do Autor, 1997. 